\title{
EDUCAÇÃO FÍSICA ESCOLAR E AS TRÊS DIMENSÕES DO CONTEÚDO: TEMATIZANDO AS DANÇAS NA ESCOLA PÚBLICA
}

\author{
Daniel Teixeira Maldonado, Universidade São Judas Tadeu - USJT, São Paulo - Brasil \\ Daniel Bocchini, Prefeitura Municipal de São Paulo, São Paulo-Brasil
}

\begin{abstract}
RESUMO
Este estudo descreve uma experiência pedagógica nas aulas de Educação Física onde os autores tematizaram as danças. Realizado durante $o 1^{\circ}$ semestre de 2013, para alunos do $6^{\circ}$ ano do ensino fundamental de uma escola municipal localizada na zona leste do município de São Paulo, a pesquisa teve como enfoque as três dimensões do conteúdo. Na dimensão procedimental, os alunos vivenciaram algumas danças (forró, catira, frevo, axé, funk, carimbó e chula) de acordo com as possibilidades de material, infraestrutura e habilidade motora no contexto escolar. Na dimensão conceitual foram realizadas aulas expositivas, análise de filmes e debates para que os alunos compreendessem o contexto histórico, as principais características e as regiões do país que essas danças são mais realizadas. $\mathrm{Na}$ dimensão atitudinal foram realizadas discussões envolvendo a diversidade cultural das danças no Brasil, problematizando no debate questões de gênero, etnias e opção sexual. Após o desenvolvimento dessa experiência pedagógica, os alunos construíram uma visão diferenciada das danças realizadas, compreenderam a história, as características e diversidade de danças e culturas existentes no país e refletiram sobre a importância de vivenciar outras manifestações da cultura corporal de movimento na escola pública.
\end{abstract}

Palavras-Chave: Educação Física escolar; Danças; Prática pedagógica.

\section{SCHOOL PHYSICAL EDUCATION AND THREE DIMENSIONS OF CONTENTS: THEMATISING DANCES IN PUBLIC SCHOOL}

\begin{abstract}
This study describes a teaching experience in physical education classes where the authors taught the dances. Performed during the 1st half of 2013, for students in the 6th grade of elementary school, a public school located on the east side of São Paulo, the research was to approach the three dimensions of content. In procedural dimension students experienced some dances (Forró, Catira, Frevo, Axé, Funk, Carimbó and Chula) according to the possibilities of material, infrastructure and motor skills in the school context. In conceptual dimension lectures, film analysis and debates were held for students to understand the historical context, major characteristics and regions of the country that these dances are performed more. Attitudinal dimension in discussions involving the cultural diversity of the dances in Brazil, discussing the debate issues of gender, ethnicity and sexual orientation were performed. After the development of this educational experience, students built a differentiated view of the dances performed, understand the history, characteristics and diversity of dances and cultures in the country and reflected on the importance of experiencing other manifestations of the culture of body movement in public school.
\end{abstract}

Conexões: revista da Faculdade de Educação Física da UNICAMP, Campinas, v. 12, n. 1, p. 181-200, jan./mar. 2014. ISSN: 1983-9030 
Key-Words: Physical Education; Dance; Teaching practice.

\section{ESCUELA EDUCACIÓN FÍSICA Y TRES DIMENSIONES DE CONTENIDOS: ENSEÑNANZA BAILES EN LA ESCUELA PÚBLICA}

\section{RESUMEN}

Este estudio describe una experiencia docente en las clases de educación física donde los autores enseñan los bailes. Realizado durante la primera mitad de 2013, para los alumnos del sexto grado de la escuela primaria, una escuela pública ubicada en la zona este de São Paulo, la investigación era acercarse a las tres dimensiones del contenido. En los estudiantes de dimensiones procesales experimentado algunos bailes (Forró Catira, Frevo, Axé, Funk, Carimbó y Chula) de acuerdo a las posibilidades de materiales, infraestructura y habilidades motoras en el contexto escolar. En conceptual se celebraron conferencias de dimensiones, el análisis de películas y debates para que los estudiantes comprendan el contexto histórico, las características principales y las regiones del país que estas danzas se realizan más. Dimensión actitudinal en los debates relacionados con la diversidad cultural de los bailes en Brasil, discutiendo los temas de debate de género, se realizaron etnia y orientación sexual. Tras el desarrollo de esta experiencia educativa, los estudiantes construyeron una visión diferenciada de las danzas ejecutadas, entender la historia, características y diversidad de bailes y culturas en el país y se refleja en la importancia de conocer otras manifestaciones de la cultura del movimiento corporal en la escuela pública.

Palabras-Clave: Educación Física; Danza; Práctica docente. 


\section{INTRODUÇÃO}

A partir da década de 1980, as ciências sociais e humanas começam a entrar na construção das teorias pedagógicas da Educação Física, surgindo uma análise crítica do paradigma da aptidão física, que permeava todas as teorias e currículos dessa área de conhecimento. Nesse momento, nasce o movimento renovador da Educação Física brasileira, onde muitos docentes procuram programas de pós-graduação. Com a influência desses professores, esse componente curricular passa a incorporar discussões pedagógicas influenciadas pelas ciências humanas, principalmente a filosofia e a sociologia da educação de orientação marxista. ${ }^{1}$

Para Bracht, ${ }^{1}$ em um primeiro momento, as análises realizadas pelos professores que faziam parte desse movimento renovador da Educação Física brasileira apenas descreviam denúncias sobre a maneira de ministrar as aulas dessa disciplina na escola. Após muitos anos de discussões e debates, já passou a ser possível identificar um conjunto de propostas com diferenças importantes.

Darido $^{2}$ constrói um resumo de todas as propostas de Educação Física que surgiram após o inicio desse movimento renovador. Todas essas ideias elaboradas tinham como principal intenção romper com o modelo esportivista e da melhora dos padrões físicos das pessoas. Importante ressaltar que muitas dessas propostas também foram influenciadas por teorias da psicologia. Os principais autores dessas propostas foram Betti, ${ }^{3}$ Brasil, ${ }^{4}$ Broto, ${ }^{5}$ Soares et al., ${ }^{6}$ Freire, ${ }^{7}$ Guedes, ${ }^{8-9}$ Kunz, ${ }^{10}$ Le Boulch, ${ }^{11}$ e Tani et al., ${ }^{12}$.

No final do século XX e início do século XXI, começam a surgir propostas curriculares de Educação Física para a rede pública de ensino por todo o Brasil. Essas propostas nascem em consonância com os Parâmetros Curriculares Nacionais. Todos esses documentos propõem uma Educação Física que entenda o ser humano de forma integral, diversifica os conteúdos se baseando nas manifestações da cultura corporal de movimento, amplia as estratégias para ensinar e cria novos critérios de avaliação.

Conexões: revista da Faculdade de Educação Física da UNICAMP, Campinas, v. 12, n. 1, p. 181-200, jan./mar. 2014. ISSN: 1983-9030 
Após o lançamento de todos esses documentos citados anteriormente, começa-se a discutir com mais ênfase uma prática pedagógica que se efetive com estratégias que ampliem apenas o fazer pelo fazer. Sendo assim, o papel desse componente curricular ultrapassou o ensino dos temas da cultura corporal como apenas seus fundamentos e técnicas. $\mathrm{O}$ professor também necessita pensar nos conceitos que estão ligados aos procedimentos selecionados e nas reflexões que possam causar mudanças de atitudes dos alunos em relação aos conteúdos explorados nas aulas. ${ }^{13}$

Influenciados por todas as discussões e debates realizados pelos docentes de Educação Física que discutem os currículos da escola, González e Fenstesrseifer ${ }^{14}$ acreditam que a Educação Física passou a ser considerada, nas últimas décadas, pelos acadêmicos e pela legislação, como um componente curricular. Dessa forma, essa disciplina escolar possui a finalidade de formar pessoas com consciência crítica para agir com autonomia em relação às manifestações da cultura corporal de movimento e munir o sujeito de possibilidades de se tornar um cidadão.

Mergulhados em todos esses debates sobre os currículos escolares, nos tornamos professores de Educação Física em escolas municipais de São Paulo. Para embasar a nossa prática pedagógica, planejamos ensinar os nossos conteúdos enfatizando as três dimensões do conteúdo. Nesse sentido, descreveremos nossa experiência de tematizar um dos conteúdos da cultura de corporal de movimento (danças), se preocupando em possibilitar vivências das diferentes danças realizadas no Brasil, debater sobre as principais características dessas danças e refletir sobre as diferenças de gênero e etnias das pessoas que praticam essas danças ao redor do país, com a intenção de tornar os nossos alunos do $6^{\circ}$ ano do ensino fundamental, sujeitos que possam atuar como cidadãos críticos e participativos na sociedade contemporânea. 


\section{MÉTODO}

Realizamos um relato de experiência de uma prática pedagógica desenvolvida em uma escola municipal, localizada na zona leste da cidade de São Paulo, com alunos do $6^{\circ}$ ano do Ensino Fundamental, entre os meses de fevereiro e julho do ano de 2013. Embasamos-nos na etnografia para coletarmos os dados no cotidiano escolar. Utilizamos diários de campo e fotografamos as aulas para expressar nossas experiências nesse artigo.

Para Molina Neto, ${ }^{15}$ a etnografia é uma metodologia de pesquisa que vem sendo muito utilizada nos estudos realizados pelos pesquisadores que se preocupam com questões educacionais. Esse tipo de pesquisa qualitativa também vem sendo utilizado em projetos de inovação pedagógica, já que possibilita uma relação bastante interativa entre o sujeito e o objeto da investigação. É nessa linha que o sujeito alcança o papel de redescobridor da cultura que vivencia cotidianamente.

Portanto, a etnografia é uma importante metodologia para compreender questões relacionadas com a escola, podendo ser um instrumento satisfatório para que os professores possam produzir conhecimento a partir da prática cotidiana e refletir sobre a sua intervenção nos ambientes escolares, além de sistematizá-la e torná-la pública. ${ }^{15}$ Nesse sentido, decidimos mencionar a nossa experiência de tematizar as danças para os nossos alunos enfatizando as três dimensões do conteúdo.

\section{RESULTADOS E DISCUSSÃO}

Ao iniciarmos o ano de 2013, tivemos a oportunidade de ministrar aula para o $6^{\circ}$ ano do Ensino Fundamental. Nós já estávamos com essas turmas desde o ano anterior e já tínhamos tematizado com esses alunos as lutas, brincadeiras e ginásticas. Decidimos então realizar um módulo de dança, pois essa manifestação da cultura corporal de movimento ainda não tinha sido discutida com os discentes.

Assustamos-nos um pouco com esse tema, pois não tínhamos nenhuma experiência com dança e a nossa formação pouco enfatizou essas práticas corporais, mas resolvemos 
encarar o desafio e construir uma prática pedagógica de dança em conjunto com os alunos dessa escola.

Além disso, os professores decidiram em conjunto que o projeto político pedagógico da escola iria estimular o protagonismo juvenil, o trabalho com as diferenças e reforçar a compreensão da leitura e da escrita dos alunos. Nesse sentido, a disciplina de Educação Física deveria selecionar conteúdos e estratégias que também atingissem esses objetivos.

Ao realizarmos o nosso planejamento, traçamos os seguintes objetivos para as aulas: vivenciar algumas danças de diferentes regiões do país; compreender a cultura que cada uma das danças regionais estão inseridas; debater sobre a quantidade de danças existentes no Brasil e os motivos dessa diversidade cultural; e refletir sobre a participação de homens e mulheres, negros, brancos e pessoas com diversas opções sexuais nas danças em diferentes regiões do país, discutindo enfaticamente o preconceito existente nessa prática corporal.

A maioria das atividades que foram realizadas surgiu durante o andamento das aulas e com a realização de pesquisas sobre o tema, pois, como citado anteriormente, não tínhamos nenhuma experiência na nossa formação inicial sobre as danças e também não somos praticantes de nenhuma dança específica. Os alunos também ajudaram muito a desenvolver o tema, pois a maioria deles se envolveu nas aulas, realizaram as pesquisas solicitadas e participaram das danças quando estimulados.

A seguir, explicaremos as dinâmicas propostas para os alunos durante as aulas de Educação Física. Primeiramente, descreveremos as experiências que estiveram relacionadas com os conceitos desenvolvidos durante as aulas, logo após mostraremos as estratégias utilizadas para os alunos realizarem as danças e para finalizar ressaltaremos quais foram as reflexões e os debates realizados sobre essa temática. Importante ressaltar que essa separação das experiências obtidas em aula foram sistematizadas apenas para melhor compreensão do leitor. No complexo do cotidiano escolar, esses aprendizados ocorreram ao mesmo tempo, de acordo com cada dinâmica que estava sendo realizada.

Conexões: revista da Faculdade de Educação Física da UNICAMP, Campinas, v. 12, n. 1, p. 181-200, jan./mar. 2014. ISSN: 1983-9030 


\section{DESENVOLVIMENTO DA PRÁTICA PEDAGÓGICA}

Para iniciar as aulas de danças regionais, realizamos algumas aulas expositivas, com a intenção de explicar dobre a diversidade rítmica existente no Brasil, mostrar quais são as diferentes regiões desse país (Norte, Nordeste, Centro-Oeste, Sudeste e Sul) e descrever algumas danças dessas regiões.

Após esse primeiro momento, fomos para a sala de vídeo e assistimos filmes retirados do youtube que mostravam diferentes danças de diversas regiões do Brasil. Assistimos como se realiza o xaxado, o forró, o carimbo, a dança do siriri, a chula, a catira, o frevo, o bumba meu boi, o samba e o funk. Nesse momento, pedimos aos alunos que anotassem a forma de realizar os movimentos dessas danças e realizassem uma reflexão do nível de dificuldade de realizar essas práticas corporais.

Após assistir aos vídeos, dividimos os alunos em cinco grupos e solicitamos que eles pesquisassem as danças da região que foi sorteada para o seu grupo. Na aula seguinte, os discentes trouxeram todo o material encontrado e realizamos alguns cartazes das diferentes danças existentes no Brasil. Abaixo, mostraremos algumas imagens dos trabalhos realizados pelos alunos. 


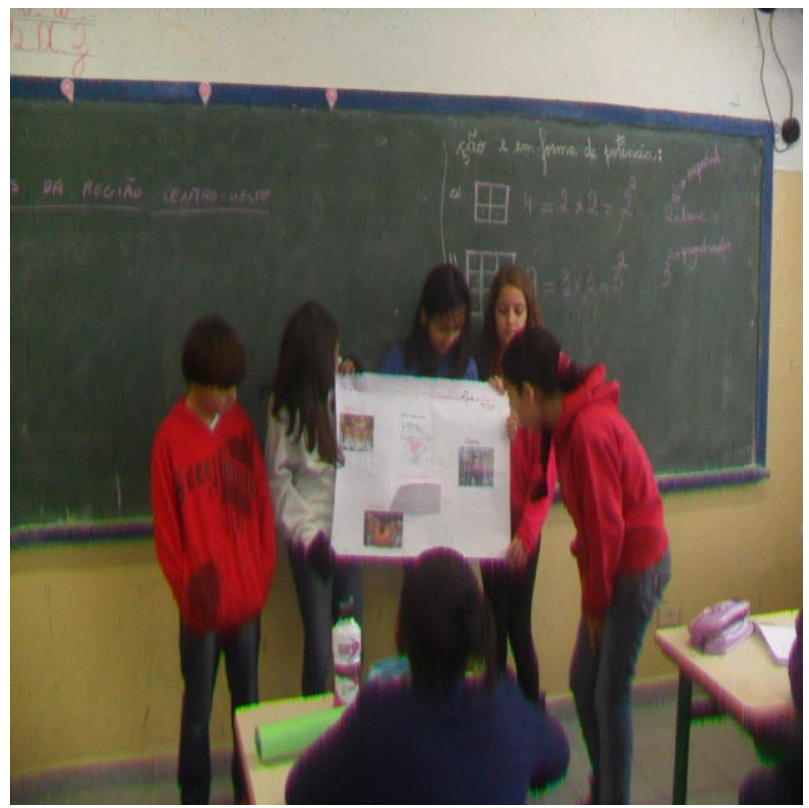

Figura 1: Alunos apresentando os cartazes de danças das diferentes regiões do país

Após a realização dos trabalhos, os estudantes apresentaram as suas pesquisas para o restante da turma, que anotaram as principais danças das diferentes regiões do Brasil encontradas pelos grupos. Nesse momento, os grupos escolheram uma das danças pesquisada para ensaiar e apresentar na escola durante as aulas de Educação Física.

Os grupos escolheram diferentes danças de cada região do Brasil para realizar uma apresentação na escola. Obviamente, nenhum dos alunos reproduziu as danças exatamente da forma que elas são realizadas. Os estudantes elaboraram coreografias ressignificando essas práticas corporais. Alguns grupos realizaram a catira para representar o Sudeste e o Centro-Oeste, outros grupos realizaram uma mistura do frevo com o axé para representar o Nordeste, alguns alunos escolheram realizar o carimbó para representar o Norte e a chula para representar a região Sul. Também houve apresentações de funk, axé e samba. Importante ressaltar todos os grupos trouxeram as músicas em um cd ou no pen drive e alguns alunos preparam uma vestimenta para realizar as apresentações Abaixo, segue as fotos de algumas danças realizadas. 


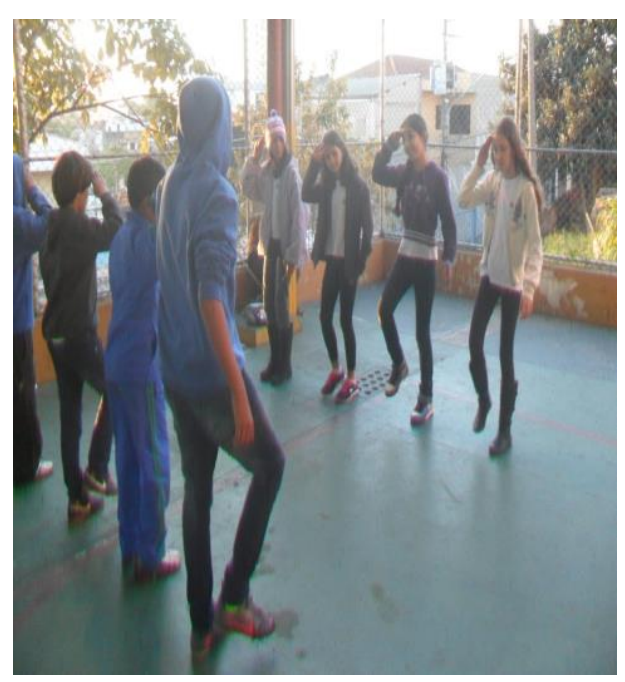

Figura 2: Catira

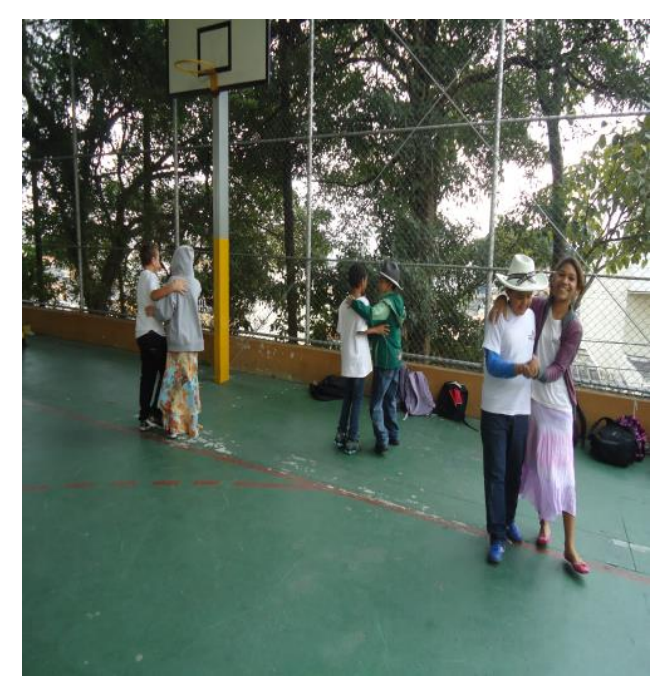

Figura 3: Carimbó

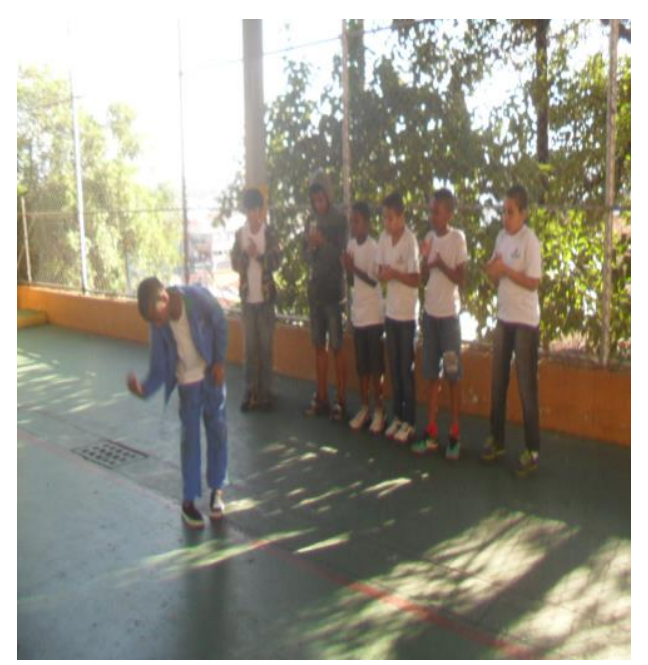

Figura 4: Chula

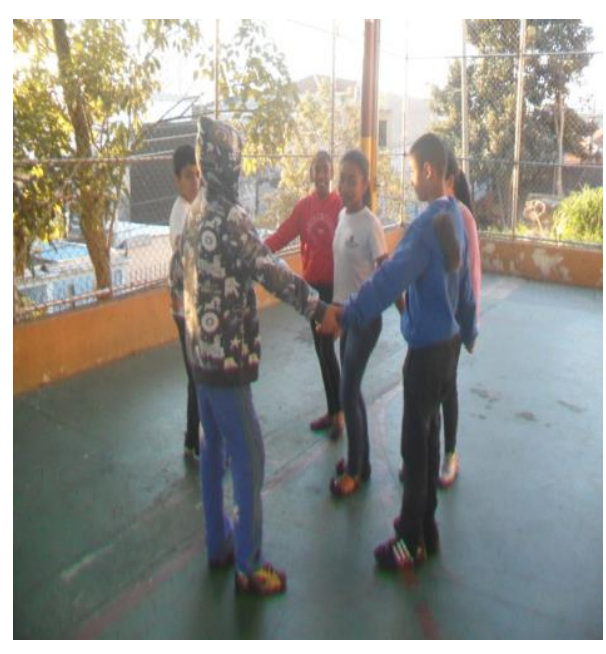

Figura 5: Samba

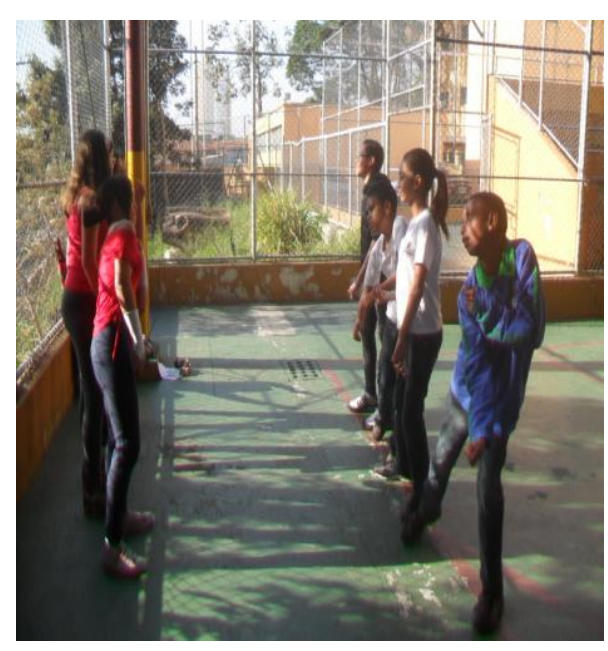

Figura 6: Axé

Conexões: revista da Faculdade de Educação Física da UNICAMP, Campinas, v. 12, n. 1, p. 181-200, jan./mar. 2014. ISSN: 1983-9030 
$\mathrm{O}$ aspecto mais interessante das aulas foi ajudar os alunos a criar uma dança parecida com aquela que eles escolheram. Como nós não tínhamos nenhuma experiência anterior com essas práticas corporais e foi a primeira vez que tematizamos esse conteúdo na escola, tivemos muitas dificuldades para ajudar os alunos a criarem as coreografias.

Chamou-nos a atenção a forma que alguns estudantes realizaram as suas danças. Um grupo decidiu misturar o axé com o frevo, já que a sua região era a Nordeste. Ficou muito interessante a apresentação que eles realizaram, pois os alunos construíram a sua apresentação de acordo com o seu repertório motor e forma de agir no mundo. No grupo do carimbó, uma das alunas já tinha realizado essa dança em outra escola e ajudou o restante dos alunos a criarem a coreografia. No grupo da chula, formado só por meninos, eles realizaram passos com os pés muito complexos e realizaram uma disputa entre eles para ver quem conseguia fazer o movimento mais difícil e o grupo de forró foi aprendendo alguns movimentos com os colegas que sabiam dançar e foram criando a sua coreografia.

Gostaríamos ainda de comentar a estratégia que foi criada para que todos os grupos realizassem os seus ensaios ao mesmo tempo. Como a escola só podia ceder um aparelho de som, os grupos trouxeram caixinhas pequenas de música, gravaram as canções em pen drive e ficavam praticando em pequenos espaços. Os estudantes que não tinham esse material pegavam emprestados dos colegas na sua vez de ensaiar. Essa dinâmica facilitou o andamento das aulas, já que todos os grupos podiam ensaiar ao mesmo tempo as danças escolhidas.

Em nenhum momento a nossa intenção foi criar coreografias de movimentos estereotipados ou cobrar a técnica perfeita das danças. Tínhamos como objetivo que os alunos realizassem as coreografias de acordo com as suas possibilidades. Acreditamos que é exatamente essa movimentação com sentido e de acordo com os repertórios de cada indivíduo que deve ser levada em consideração durante as aulas de Educação Física na escola, respeitando aqueles alunos que possuem um grande nível de habilidade e conseguem realizar movimentos complexos e aqueles que possuem pouco repertório motor e realizam movimentos mais simples. 
Durante essas apresentações começamos a perceber o preconceito dos meninos em relação às práticas corporais relacionadas com a dança e sabíamos que esse seria um grande desafio. Durante as nossas reflexões, mostramos que existem danças que são realizadas por homens e que muitas outras são realizadas por homens e mulheres. A nossa maior dificuldade foi realizar um debate sobre a opção sexual das pessoas que escolhem praticar algum tipo de dança. Muitos meninos costumavam dizer que alguns determinados tipos de movimentos eram realizados apenas por homossexuais.

Identificamos que durante as vivências de dança e as discussões relacionadas com a diversidade rítmica brasileira, alguns meninos conseguiram compreender melhor o sentido de dançar, mas muitos outros continuaram com o mesmo preconceito de antes. Pensamos que esse comportamento era normal para alunos do $6^{\circ}$ ano do Ensino Fundamental, além disso, não tínhamos a intenção de mudar nenhum tipo de comportamento, pois nosso maior objetivo era mostrar outra forma de compreender a relação de gênero com as danças e permitir que os alunos formassem as suas próprias opiniões em relação ao tema proposto, mas somente depois de ouvirem diferentes opiniões sobre a questão.

Outro aspecto importante que foi levantado nesse momento esteve relacionado com as danças que estão sendo realizadas na atualidade. Em todas as salas de aula tivemos a oportunidade de discutir como que as letras e os movimentos cheios de sensualidade de alguns ritmos musicais estão sendo realizados. Percebemos que muitos adolescentes gostavam dessas músicas e de dançar esses ritmos, mas também, muitos alunos não gostavam desses ritmos recentes. Tentamos enfatizar nas discussões a exploração da sexualidade em algumas dessas músicas e os movimentos sensuais que são realizados nelas, discutimos também a utilização de drogas em alguns bailes para adolescentes e também surgiu um debate sobre a gravidez na adolescência, pois em alguns desses bailes meninos e meninas já têm relação sexual.

Também foram levantadas discussões sobre danças de brancos e danças de negros. Discutimos porque em muitos contextos o balé é tido como dança de brancos e o hip hop como dança de negros. Durante essas reflexões, mencionamos que existe um aspecto Conexões: revista da Faculdade de Educação Física da UNICAMP, Campinas, v. 12, n. 1, p. 181-200, jan./mar. 2014. ISSN: 1983-9030 
cultural inserido nesse diagnóstico e que tanto as pessoas brancas podem se interessar por hip hop, como as pessoas negras podem se interessar por balé. Um filme que discute muito essas questões e que utilizamos para causar reflexões nos estudantes foi 'No Balanço do Amor'. Assistimos ao filme durante as aulas na escola e pedimos que os alunos respondessem a seguinte questão: existem danças para pessoas de pele negra e danças para pessoas de pele branca? A maioria dos alunos entendeu o filme e respondeu que culturalmente isso existe, mas que as pessoas precisam respeitar a vontade dos outros e cada ser humano pode dançar o ritmo musical que desejar, independente da sua cor, etnia, opção sexual ou gênero. Também mencionamos o contexto histórico de diversas danças para explicar porque certas práticas corporais eram mais praticadas por pessoas de etnias diferentes. Abaixo, encontra-se um desenho que os alunos realizaram ao analisar o filme assistido.

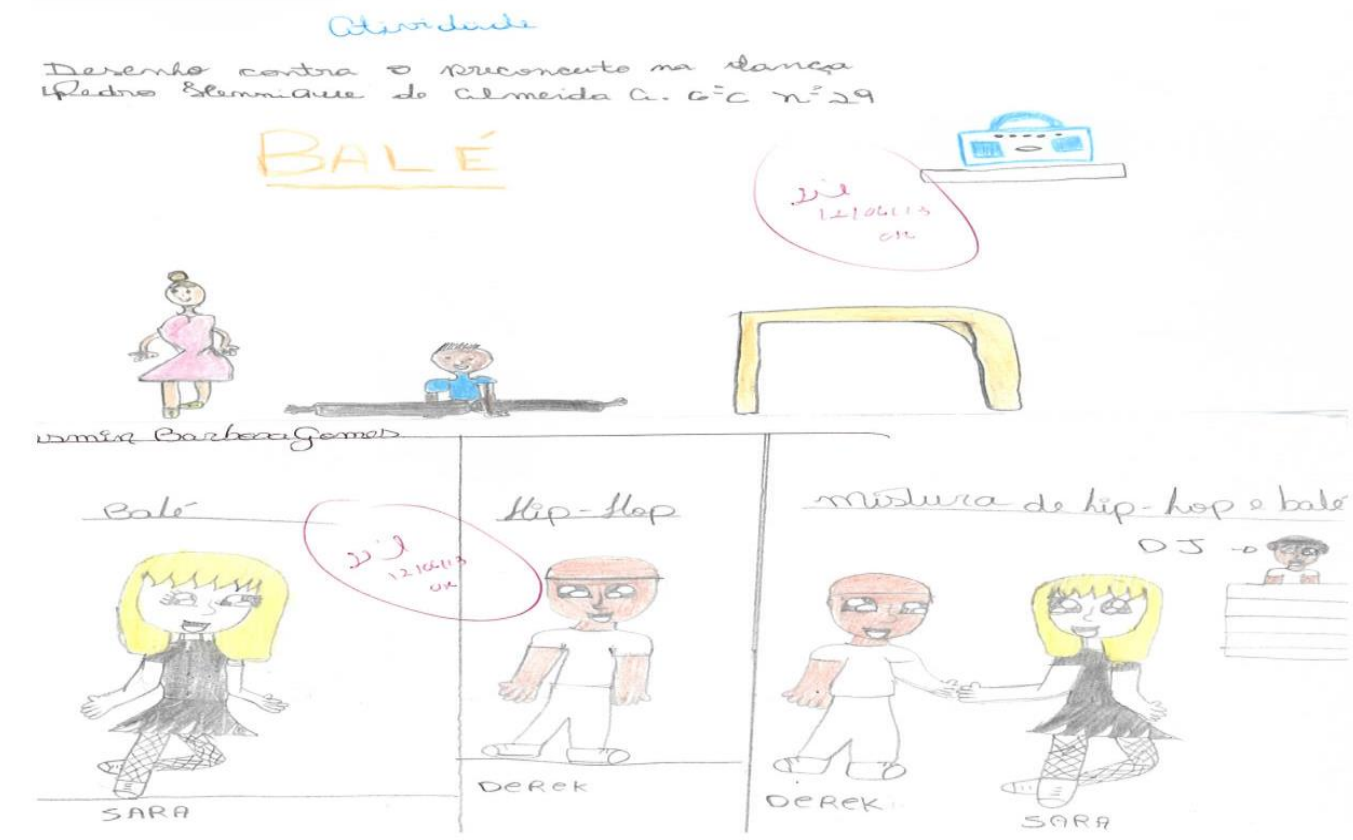

Figura 7: Trabalho sobre preconceito nas danças realizado pelos alunos

Também realizamos um debate em sala de aula sobre o funk. Esse ritmo musical é muito escutado pelos alunos e tem sido palco de diversos debates na sociedade brasileira. Levantamos questões sobre as letras das músicas que exploram a sexualidade e a ostentação, além de discutir com os alunos que existe também um estilo de funk mais Conexões: revista da Faculdade de Educação Física da UNICAMP, Campinas, v. 12, n. 1, p. 181-200, jan./mar. 2014. ISSN: $1983-9030$ 
crítico, que fala sobre a triste realidade que algumas pessoas vivem no Brasil. Analisamos a música do MC Garden chamada 'Isso é o Brasil', que discute sobre a violência da polícia, a discriminação contra os homossexuais e a corrupção no Brasil. Após essa análise, solicitamos aos alunos que eles escrevessem uma letra de Funk que relatasse algo que os indignassem. Descreveremos a seguir, a letra de uma menina que nos chamou atenção.

\title{
O Brasil
}

De que adianta você trabalhar duro

Se você sabe que o homem ganha mais que a mulher

Se não lutar agora, esse será o futuro

Porque ainda não acabou o machismo

Não existem muitos negros ricos

Sendo que em bairro de pobre não tem nada

Álcool e as drogas já tomaram conta

Se bobear já estamos fritos

Já li em revistas o que dizem sobre os homossexuais

Já disseram que querem dominar o mundo

Ou que isso é doença

Por que não acabou o preconceito?

Se você ficou doente vai ter que esperar

Mas se for rico terá o melhor atendimento

Esse é o Brasil

Por que não acabou a diferença?

\author{
Não querem ajudar \\ Eles só vão piorar
}

Não feche os olhos e finja que não viu

Lute agora e mude o Brasil

Conexões: revista da Faculdade de Educação Física da UNICAMP, Campinas, v. 12, n. 1, p. 181-200, jan./mar. 2014. ISSN: 1983-9030 
Outros alunos também escreveram as suas letras de funk e alguns realizaram desenhos para mostrar a sua indignação sobre a sua realidade. A seguir, encontra-se um desenho realizado pelos alunos.

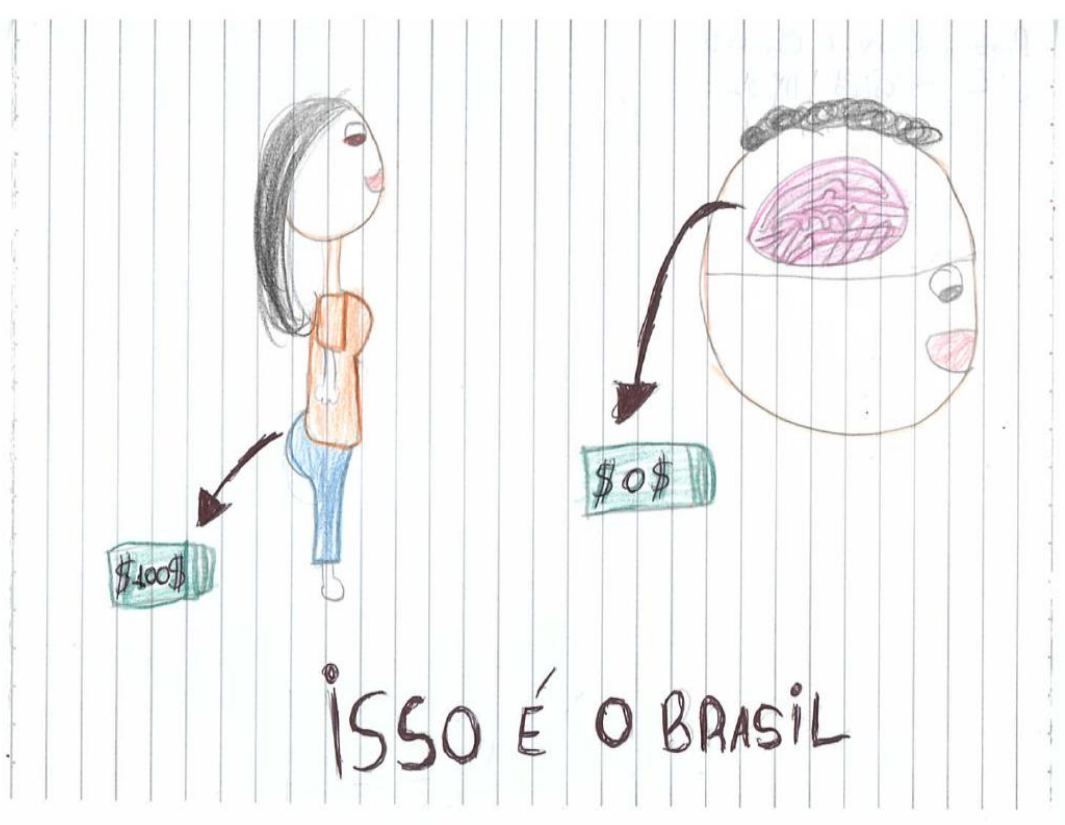

Figura 8: O corpo vale mais que a inteligência

Utilizamos todos os trabalhos dos alunos para realizar a avaliação do processo de ensino e aprendizagem, além de nossa prova formal, que é realizada todo o final de bimestre. O conceito emitido para os alunos durante as nossas aulas de Educação Física foram produzidos a partir da participação nas danças realizadas, das notas recebidas pelos trabalhos, pela participação nas discussões em aula e pela nota recebida na prova.

Diversos pesquisadores que se preocupam em mostrar práticas pedagógicas inovadoras, pautadas nas três dimensões do conteúdo, também publicaram os seus estudos em periódicos científicos, com a intenção de compartilhar essas experiências pedagógicas que estão sendo realizadas no "chão das escolas". Rodrigues e Darido ${ }^{16}$ relataram uma Conexões: revista da Faculdade de Educação Física da UNICAMP, Campinas, v. 12, n. 1, p. 181-200, jan./mar. 2014. ISSN: 1983-9030 
experiência onde a professora ensinou diversos conteúdos da cultura corporal de movimento, para alunos do $6^{\circ}$ ano do ensino fundamental, durante as aulas de Educação Física, levando em consideração as três dimensões do conteúdo.

Matthiesen et al. ${ }^{17}$ descreveram um relato de experiência que versou sobre o ensino do atletismo, enfatizando os saberes de atitudes, procedimentos e conceitos dessa manifestação da cultura corporal de movimento. Os autores enfatizaram que foram encontradas diversas dificuldades durante as aulas observadas, mas conseguiram superar esses problemas e ensinar diversas modalidades do atletismo na escola.

Também encontramos um estudo realizado com a metodologia de pesquisa-ação, onde os autores tiveram como objetivo implementar e avaliar uma proposta de voleibol na escola pública, pautada pelas três dimensões do conteúdo. Os resultados da pesquisa mostraram que os docentes dessa escola conseguiram implementar um trabalho de qualidade, embora tenham encontrado algumas dificuldades durante a sua prática pedagógica. ${ }^{18}$

Maldonado e Bocchini ${ }^{19}$ produziram uma experiência pedagógica realizada na escola pública, durante as aulas de Educação Física, com alunos do $3^{\circ}$ ano do Ensino Fundamental, enfatizando o ensino das ginásticas: rítmica, artística, acrobática e geral, baseada nas três dimensões do conteúdo. Os autores utilizaram materiais alternativos para vivenciar essas práticas corporais com os seus alunos, além de refletirem sobre os preconceitos de gênero e etnia existentes nesses diferentes tipos de ginásticas.

Maldonado e Bocchini ${ }^{20}$ também publicaram uma experiência pedagógica tematizada com alunos do $5^{\circ}$ ano do ensino fundamental, com alunos de uma escola pública localizada na zona leste de São Paulo, enfatizando o ensino das lutas nas três dimensões do conteúdo. Os autores encontraram dificuldades de materiais e infraestrutura para implementarem as suas aulas, mas também as superaram utilizando materiais alternativos e respeitando o nível de habilidade motora de cada um dos alunos das suas turmas.

Conexões: revista da Faculdade de Educação Física da UNICAMP, Campinas, v. 12, n. 1, p. 181-200, jan./mar. 2014. ISSN: 1983-9030 
Mascara et al. $^{21}$ apresentaram uma proposta de futebol baseada nas três dimensões do conteúdo e dividiram o planejamento das aulas em cinco partes (roda inicial, jogo adaptado ou brincadeira, exercício preferencialmente lúdico, jogo adaptado ou brincadeira e roda final).

Como podemos perceber, são muitos os autores que publicaram experiências pedagógicas inovadoras realizadas na escola. Em todos esses estudos, os professores de Educação Física se preocuparam em ensinar os seus conteúdos enfatizando os procedimentos, os conceitos e as atitudes existentes naquela prática corporal, proporcionando aos seus alunos uma variedade de aprendizagens, com a intenção de torná-los cidadãos com maior consciência crítica para atuar na sociedade.

\section{DIFICULDADES PARA REALIZAR A EXPERIÊNCIA PEDAGÓGICA}

Durante as aulas de danças nessa escola, nossa maior dificuldade foi a resistência dos alunos com o conteúdo. Os outros docentes de Educação Física dessa unidade escolar realizavam um trabalho mais voltado para as competições esportivas e tivemos muitos obstáculos para os discentes entenderem a nossa proposta. No início, muitos adolescentes se recusavam a participar da aula ou participavam de qualquer jeito, mas com o tempo as coisas foram melhorando e as aulas ocorreram de forma satisfatória. Uma das nossas estratégias foi realizar acordos, sendo assim, depois de cada tema tematizado, nós deixávamos durante uma semana que os alunos praticassem as atividades esportivas que mais gostassem. Importante ressaltar que esse já era o nosso segundo ano com a turma e eles já estavam começando a entender a nossa proposta de trabalho.

A nossa inexperiência com dança também foi um fator dificultador. A nossa formação profissional tratou muito pouco desse conteúdo na escola e nossa trajetória pessoal também não possibilitou muitas vivências de dançar. Tivemos que realizar pesquisas, utilizamos algumas estratégias propostas em livros de Educação Física e criamos outras dinâmicas de acordo com as situações que ocorriam nas aulas. A facilidade de retirar vídeos da internet nos ajudou muito para alcançarmos os nossos objetivos.

Conexões: revista da Faculdade de Educação Física da UNICAMP, Campinas, v. 12, n. 1, p. 181-200, jan./mar. 2014. ISSN: 1983-9030 
Tivemos alguns problemas de indisciplina em algumas turmas. Parece-nos que quando se inicia um trabalho novo em uma escola, os alunos testam o professor para saber quais são os seus limites e não foi diferente conosco. Primeiramente, alguns alunos não queriam realizar as atividades, nos desrespeitavam durante as aulas e alguns foram reclamar com a direção da escola porque queríamos ficar na sala de aula em alguns momentos. Acreditamos que no primeiro mês de aula houve muitos conflitos, que foram sendo minimizados com o passar do tempo.

Propor dinâmicas em que os meninos necessitam dançar também foi uma dificuldade. A vergonha de se expor ou de cometer algum erro faz com que muitas crianças e adolescentes não queiram participar, além da cobrança da sociedade com a opção sexual dos alunos, como se dançar estivesse demonstrando que a pessoa é homossexual ou heterossexual. Tivemos que discutir sobre isso durante as aulas e esse assunto é sempre delicado e polêmico. Essas discussões tiveram pontos positivos e negativos, mas é sempre melhor propor o debate do que permanecer com uma opinião cristalizada de um assunto como esse.

\section{REFLEXÕES FINAIS}

Ao terminar o módulo e as vivências de dança com essas turmas, acreditamos que os alunos compreenderam sobre a diversidade rítmica existente no Brasil, refletiram sobre os preconceitos existentes com as diferentes formas de danças e realizaram vivências ressignificando essas práticas corporais, de acordo com o seu repertório motor e as suas vivências anteriores.

Houve muitos obstáculos durante a tematização desse conteúdo na escola. A resistência dos alunos frente ao novo conteúdo e ao formato das aulas de Educação Física, os preconceitos dos próprios adolescentes com a dança e a indisciplina dificultaram bastante o processo, mas foram superados na medida do possível.

Desenvolver um módulo com a temática dança foi um grande desafio e temos certeza que algumas das nossas estratégias ocorreram de forma positiva devido a seriedade que o Conexões: revista da Faculdade de Educação Física da UNICAMP, Campinas, v. 12, n. 1, p. 181-200, jan./mar. 2014. ISSN: 1983-9030 
trabalho foi conduzido e a postura dos alunos com os estudos, que foi melhorando de forma significativa com o passar do tempo. Terminamos as aulas de dança com a certeza de que os objetivos traçados no inicio do planejamento foram alcançados, principalmente porque as avaliações realizadas durante o processo demonstravam que os discentes tinham compreendido o conteúdo e os debates de ordem social que foram realizados durante as aulas.

\section{REFERÊNCIAS}

${ }^{1}$ BRACTH, V. A constituição das teorias pedagógicas da Educação Física. Caderno Cedes, Campinas, ano 19, n. 48, ago. 1999.

${ }^{2}$ DARIDO, S. C. Educação Física na escola: questões e reflexões. Rio de Janeiro: Guanabara Koogan, 2003.

${ }^{3}$ BETTI, M. Educação Física e sociedade: a Educação Física na escola brasileira de $1^{\circ}$ e $2^{\circ}$ graus . São Paulo: Movimento, 1991.

${ }^{4}$ BRASIL. Ministério da Educação e Cultura. Secretaria de Educação Fundamental. Parâmetros Curriculares Nacionais: Educação Física. Brasília, 1998..

${ }^{5}$ BROTO, F. O. Jogos cooperativos: se o importante é competir, o fundamental é cooperar. São Paulo: Cepeusp, 1995.

${ }^{6}$ SOARES, C. L. et al. Metodologia do ensino de Educação Física. São Paulo: Cortez, 1993.

${ }^{7}$ FREIRE, J. B. Educação de corpo inteiro: teoria e prática da Educação Física. São Paulo: Scipione, 1989.

${ }^{8}$ GUEDES, D. P. Educação para saúde mediante programas de Educação Física escolar. Motriz, Rio Claro, v. 5, n. 1, jun. 1999.

Conexões: revista da Faculdade de Educação Física da UNICAMP, Campinas, v. 12, n. 1, p. 181-200, jan./mar. 2014. ISSN: 1983-9030 

- Educação Física Escolar com ênfase em educação para a saúde. In: CONGRESSO INTERNACIONAL DE EPISTEMOLOGIA DA EDUCAÇÃO FÍSICA, 1. 2006, São Paulo. Anais... São Paulo, 2006.

${ }^{10}$ KUNZ, E. Transformação diático-pedagógica do esporte. Ijuí: Ed. da UNIJUÍ, 2001.

${ }^{11}$ LE BOULCH, J. A educação pelo movimento: a psicocinética na idade escolar. Porto Alegre: Artes Médicas, 1983.

${ }^{12}$ TANI, G. et al. Educação Física escolar: fundamentos de uma abordagem desenvolvimentista. São Paulo: EPU, 1988.

${ }^{13}$ DARIDO, S. C. et al. A Educação Física, a formação do cidadão e os Parâmetros Curriculares Nacionais. Revista Paulista de Educação Física, São Paulo, v. 15, n. 1, p. 17-32, jan./jun. 2001.

${ }^{14}$ GONZÁLEZ, F. J.; 'FENSTERSEIFER, P. E. Entre o "não mais" e o "ainda não": pensando saídas para o não lugar da EF escolar II. Cadernos de Formação RBCE, p. 1021, mar. 2010.

${ }^{15}$ MOLINA NETO, V.; TRIVIÑOS, A. N. S. A pesquisa qualitativa na Educação Física: alternativas metodológicas. In: MOLINA NETO, V. Etonografia: opção metodológica para alguns problemas de investigação no âmbito da Educação Física. Porto Alegre: Sulina, 2010.

${ }^{16}$ RODRIGUES, H. A; DARIDO, S. C. As três dimensões do conteúdo na prática pedagógica de uma professora de Educação Física com mestrado: um estudo de caso. Revista da Educação Física/UEM, Maringá, v. 19, n. 1, p. 51-64, 2008. 
${ }^{17}$ MATTHIESEN, S. Q.; SILVA, M. F. G.; LIMA e SILVA, A. C. Atletismo na escola. Motriz, Rio Claro, v. 14, n. 1, p. 96-104, 2008.

${ }^{18}$ BARROSO, A. L. R.; DARIDO, S. C. Voleibol escolar: uma proposta de ensino na dimensão conceitual, procedimental e atitudinal do conteúdo. Revista Brasileira de Educação Física e Esporte, São Paulo, v. 24, n. 2, p. 179-194, abr./jun. 2010.

${ }^{19}$ MALDONADO, D. T.; BOCCHINI, D. Prática pedagógica diferenciada nas aulas de Educação Física: a ginástica na escola pública. Coleção Pesquisa em Educação Física, Jundiaí, v. 12, n. 1, p. 165-172, 2013 a.

${ }^{20}$ MALDONADO, D. T.; BOCCHINI, D. As três dimensões do conteúdo na Educação Física: tematizando as lutas na escola pública. Conexões, Campinas, v. 11, n. 4, p. 195$211,2013 b$.

${ }^{21}$ MASCARA, D. I.; CHIMINAZZO, J. G. C.; LIMA, N. M. O futebol da escola: construção de uma proposta baseada nas três dimensões dos conteúdos. Pulsar, Jundiaí, v. 5, n. 1, 2013.

${ }^{22}$ DARIDO, S. C.; SOUZA JUNIOR, O. Refletindo sobre a tematização do futebol na Educação Física escolar. Motriz, Rio Claro, v. 16, n. 4, p. 920-930, 2010.

Recebido em: 24 jan. 2014

Aceito em: 04 fev. 2014 Contato: Daniel Teixeira Maldonado danieltmaldonado@yahoo.com.br 